\title{
A EFICIÊNCIA PÚBLICA MUNICIPAL COMO DIMENSÃO DO DESENVOLVIMENTO ${ }^{1}$
}

Liana Bohn²

Gabriel Teixeira Ervilha ${ }^{3}$

Cassiano Ricardo Dalberto ${ }^{4}$

0 presente estudo objetiva apresentar como a inclusão de indicadores de eficiência dos gastos públicos ao cálculo do Índice de Desenvolvimento Humano Municipal (IDHM) pode propiciar um novo prisma para a análise do desenvolvimento municipal, fornecendo um indício da qualidade de vida que poderia estar ao alcance do município caso este fizesse uso de seus recursos de maneira mais eficiente. Através da utilização da análise envoltória de dados, observa-se que uma maior eficiência, ainda que não seja o único meio para atingir maiores níveis de desenvolvimento, certamente é necessária para superar condições de baixo desenvolvimento, criando um ciclo virtuoso de oportunidades e qualidade de vida.

Palavras-chave: IDHM; análise envoltória de dados; gastos públicos.

\section{THE MUNICIPAL PUBLIC EFFICIENCY AS A DEVELOPMENT DIMENSION}

This study aims to present a new perspective to analyze municipal development through the inclusion of public spending efficiency indicators to calculate the municipal HDI, providing evidence about the life quality that could be within reach if the city were applying its resources more efficiently. By using data envelopment analysis, it is observed that although a greater efficiency isn't the single way to achieve higher levels of development, it is certainly necessary to overcome low development conditions, creating a virtuous cycle of opportunity and quality life.

Keywords: municipal HDI; data envelopment analysis; public spending.

\section{LA EFICIENCIA PÚBLICA MUNICIPAL COMO DIMENSIÓN DEL DESARROLLO}

Este estudio tiene como objetivo presentar cómo la inclusión de indicadores de eficiencia de los gastos públicos en el cálculo del IDH de los municipios puede propiciar una nueva perspectiva para el análisis del desarrollo municipal, proporcionando un indicador de calidad de vida que podría estar al alcance de la municipalidad si la misma utilizase sus recursos de manera más eficiente. Mediante el uso del análisis envolvente de datos, se observa que una mayor eficiencia, aunque no sea el único medio para alcanzar mayores niveles de desarrollo, es ciertamente necesaria para superar las condiciones de bajo desarrollo, creando un círculo virtuoso de oportunidad y calidad de vida.

Palabras clave: IDH municipal; análisis envoltorio de datos, gasto público.

1. DOI: http://dx.doi.org/10.38116/ppp56art1

2. Professora adjunta do Departamento de Economia e Relações Internacionais da Universidade Federal de Santa Catarina (UFSC).E-mail: <liana.bohn@ufsc.br>.

3. Técnico do Departamento de Economia da Universidade Federal de Viçosa (UFV).E-mail: <gabriel.ervilha@ufv.br>.

4. Professor do Departamento de Ciências Econômicas da Universidade do Estado de Santa Catarina (Esag/Udesc).

E-mail:<cassianord@gmail.com>. 


\title{
EFFICACITÉ PUBLIQUE MUNICIPALE AS DIMENSION DE DÉVELOPPEMENT
}

\begin{abstract}
Cette étude vise à se présenter comme l'inclusion d'indicateurs d'efficacité des dépenses publiques pour calculer le IDHM peut fournir une nouvelle perspective pour l'analyse du développement municipal, en fournissant un indicateur de qualité de vie qui pourrait être disponible à la municipalité si elle utilizasse ses ressources plus efficacement. En utilisant l'analyse d'enveloppement des données, on observe qu'une plus grande efficacité, mais pas le seul moyen d'atteindre des niveaux plus élevés de développement, il est certainement nécessaire pour surmonter des conditions de faible développement, créant ainsi un cercle vertueux de chances et la qualité la vie.
\end{abstract}

Mots-clés: IDHM; analyse des données envelopment; les dépenses publiques.

JEL: H21; H53; 015.

\section{INTRODUÇÃO}

Mensurar o nível de bem-estar tendo a renda como indicador per se de qualidade de vida foi se revelando, a partir dos anos 1980, cada vez mais inadequado. Disso resultou um esforço metodológico e conceitual, por parte de muitos órgãos de pesquisa e agências internacionais, que identificou medidas através das quais, por uma combinação de diferentes variáveis (não necessariamente econômicas), tornar-se-ia possível representar quantitativamente uma determinada condiçáo de progresso social. A dificuldade estaria, portanto, em definir os parâmetros, de tal modo que a combinação daí resultante fosse representativa do conceito de desenvolvimento (Hicks e Streeten, 1979).

Nos anos 1990, o Índice de Desenvolvimento Humano (IDH) surge, portanto, como uma alternativa para se verificar o nível de bem-estar de um país, utilizando-se de indicadores de desempenho e se consolidando como o mais conhecido cálculo para tal fim (Torres, Ferreira e Dini, 2003). Sua grande inovação é direcionar o debate do progresso social em termos de qualidade de vida e das condiçóes essenciais à sociedade, opondo-se às antigas mensuraçóes em que a esfera econômica do indivíduo sobressaía-se frente aos aspectos sociais inerentes a ele.

Criado para o Programa das Nações Unidas para o Desenvolvimento (PNUD), o IDH foi tradicionalmente concebido como instrumento de avaliação do grau de desenvolvimento agregado de países, o que não impediu seu posterior desdobramento como indicador de progresso social para níveis regionais menos abrangentes, como estados e municípios. Entretanto, a dificuldade de mensuração desses indicadores locais torna-se maior à medida que o território fica mais específico, especialmente em virtude do acréscimo em termos de dispêndios temporais e financeiros inerentes à captação das informaçóes necessárias.

O Brasil foi um dos pioneiros nesse processo de adequação da metodologia do IDH à realidade do país de acordo com sua disponibilidade de informaçóes, resultando no que hoje se conhece por IDH Municipal (IDHM). Construído pelo 
PNUD, em parceria com o Ipea e a Fundação João Pinheiro (FJP), o IDHM é referência para o acompanhamento do desenvolvimento socioeconômico, tanto no recorte local quanto em nível nacional, apresentando a mesma metodologia de cálculo do IDH, mas fazendo uso de alguns indicadores distintos. Esta proximidade do indicador à realidade brasileira faz dele um amparo, por exemplo, aos gestores municipais, por possibilitar a estes um exame claro das condições dos municípios e destes em comparação aos demais (PNUD, 2013).

Ainda é um desafio, entretanto, pensar em um índice que seja capaz de mensurar toda a complexidade do desenvolvimento humano, mas é possível aumentar a aplicabilidade de tais indicadores mediante a incorporação de outras dimensóes relacionadas ao bem-estar. No caso do IDHM, por exemplo, não há quaisquer referências aos esforços públicos desprendidos pelas unidades avaliadas em termos de melhorar os indicadores de longevidade, educação e renda, especialmente no contexto de restrições orçamentárias. Neste sentido, o índice de desenvolvimento computa o resultado final do processo, desconsiderando os recursos destinados para cada unidade avaliada, e não refletindo diretamente a eficiência das prefeituras no que concerne ao seu empenho em transformar o orçamento público em melhores condiçốes de vida à população (Dalberto et al., 2015).

Sendo esse o caso, dois municípios podem apresentar o mesmo valor para o IDHM ainda que façam uso de distintas quantidades de recursos. Ora, é de se esperar que aquele que aplica mais eficientemente seu orçamento consiga poupar mais e, consequentemente, tenha a possibilidade de investir em outras atividades que não são mensuradas diretamente pelo indicador, mas que impactam a qualidade de vida dos cidadãos e a qualidade dos serviços já oferecidos (como na conservação ambiental e na cultura, por exemplo). Assim, a eficiência dos gastos em componentes básicos do desenvolvimento surge como importante medida dos resultados obtidos pelos gestores municipais, podendo proporcionar mudanças nos indicadores de desenvolvimento e, consequentemente, alterar a maneira como os agentes econômicos percebem a relação entre a gestão do município e seu nível de qualidade de vida.

Seguindo o esforço de Dalberto et al. (2015) na incorporação da eficiência ao cálculo do indicador de desenvolvimento dos países, é possível questionar se, quando trazidas para os municípios brasileiros, as informaçóes referentes à qualidade de vida da população são influenciadas pela consideração dos esforços públicos direcionados aos parâmetros avaliados. Embora este questionamento seja justificável (e alvo de análise no presente estudo), o IDHM permanece sendo uma fonte de informação não apenas para a gestão pública na verificação das atuais circunstâncias, mas também como guia para os cidadãos e organismos públicos e privados na definição de políticas públicas e investimentos entre os municípios. 
Cabe a ele, portanto, não somente revelar a atual conjuntura econômico-social, mas também considerar os esforços envolvidos na busca de melhores resultados.

É nesse contexto que o presente artigo, ao incorporar a eficiência como um novo componente do IDHM, objetiva evidenciar quais municípios fazem melhor uso de seus recursos e de que maneira isso pode impactar os resultados de tal indicador de desenvolvimento. Assim, é possível fornecer um indício da qualidade de vida potencial, que sugere o que poderia estar ao alcance do município caso este utilizasse seus recursos de maneira mais eficiente. Estimada para os municípios brasileiros, a proposta de inclusão de um subíndice se dá a partir do método de análise de eficiência, denominado análise envoltória de dados (do inglês, data envelopment analysis - DEA), que também permite averiguar a ocorrência de padróes espaciais na distribuição de eficiência entre as unidades avaliadas.

Considerando as inúmeras aplicaçóes na comparação da eficiência produtiva de unidades organizacionais, a avaliação da eficiência dos gastos públicos tem se destacado diante do confronto dos dispêndios em todos os níveis governamentais e nas mais diversas áreas de gestão. Em termos da eficiência para os componentes específicos do IDHM, alguns estudos se voltam para a análise do campo educacional, como o de Meza (1998), Façanha e Marinho (2001) e Silva e Fernandes (2001); e aspectos da área de saúde e saneamento, como Marinho (2001), Castro (2003), Lins et al. (2007), Gondim (2008) e Yamada (2011). Essas aplicaçóes destacam o emprego crescente da metodologia DEA em diversas frentes, especialmente na avaliação de medidas de eficiência em políticas públicas, bem como lançam luz às possibilidades ainda não exploradas no campo do desenvolvimento econômico, que podem servir como um aparato importante na averiguação das possíveis estratégias a serem tomadas na busca da melhor gestáo municipal.

Além da presente introdução, o trabalho contém mais três seções. Na seção 2, procura-se discutir o ajustamento metodológico do IDHM para o IDHM Eficiente (IDHME); a seção 3 apresenta e examina os resultados obtidos pela pesquisa e, por fim, a seção 4 faz as consideraçôes finais.

\section{AJUSTAMENTO DO IDHM PARA O IDHME}

Para além das áreas temáticas utilizadas no IDHM (longevidade, educação e renda), o IDHME está alicerçado na elaboração de uma dimensão adicional à análise do desenvolvimento humano dos municípios brasileiros - a eficiência média. Esta, por seu turno, compreende a ideia de que o desempenho eficiente das unidades avaliadas deve ser aquele que consegue disponibilizar serviços na qualidade e na quantidade demandadas pela sociedade, consumindo-se o mínimo possível de recursos. O presente estudo avalia, portanto, como os gastos públicos em saúde e 
educação e a distribuição de renda estão contribuindo na geração do desenvolvimento municipal, medido pelo IDHM.

A determinação da eficiência é possível a partir da DEA, ${ }^{5}$ proposta originalmente por Charnes, Cooper e Rhodes (1978). Baseada em modelos matemáticos de otimização não paramétricos, este método busca avaliar unidades tomadoras de decisão (do inglês, decision making unit-DMU), ao verificar quais delas estáo inseridas na fronteira de possibilidade de produção, ou seja, examina se o desempenho destas DMUs, do ponto de vista da eficiência técnica, é ótimo. Ademais, para cada unidade ineficiente, os modelos DEA fornecem seus respectivos benchmarks (DMUs de referência), determinados pela projeção dessas unidades na fronteira de eficiência. Essa projeção, dependente da amostra, é feita neste estudo de acordo com a orientação a insumos (quando se deseja minimizar os recursos, mantendo-se os valores dos produtos constantes) e com retornos variáveis à escala, uma vez que se admite a separação dos resultados em relação à pura eficiência técnica e à eficiência de escala, permitindo-se que DMUs que operam com baixos valores de inputs (insumos) tenham retornos crescentes e as que operam com altos valores, retornos decrescentes.

A heurística proposta neste artigo consiste de três etapas, destacadas na figura 1.

FIGURA 1

Construção do Índice de Desenvolvimento Humano Municipal Eficiente

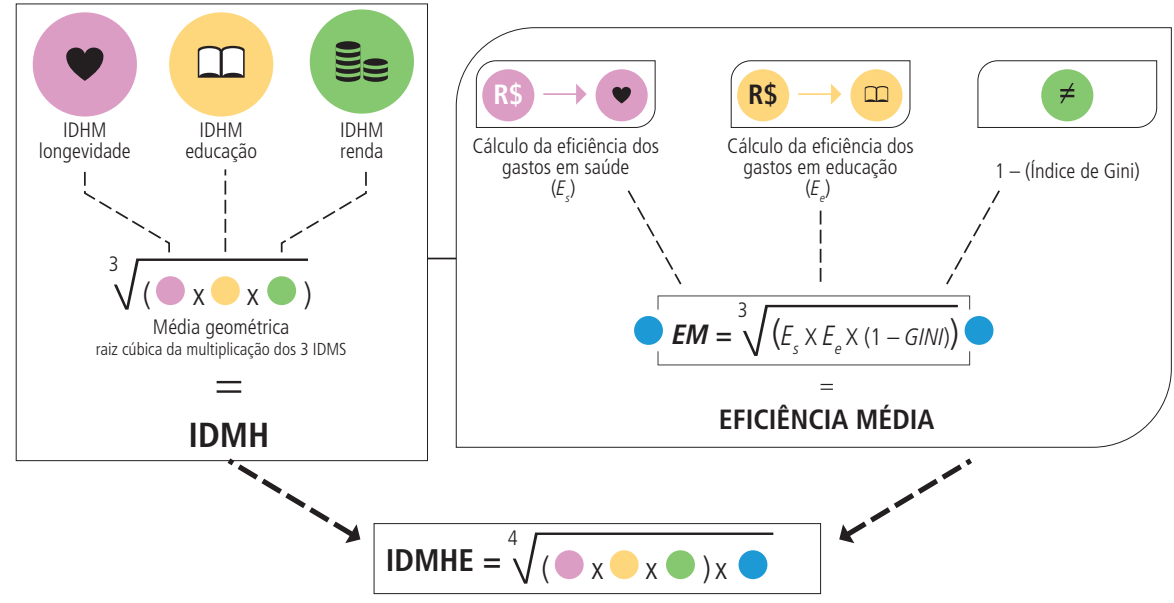

Fonte: PNUD (2013).

Elaboração dos autores. 
A primeira etapa consiste no cálculo das eficiências das dimensões do IDHM. A partir do acompanhamento da execução orçamentária dos municípios por cinco anos (2006-2010) no que concerne aos gastos municipais em saúde e educação, ${ }^{6}$ têm-se a base de dois dos insumos que são utilizados para calcular os efeitos sobre os produtos - aqui representados pelo IDHM em cada dimensão. Tomando-se, como inputs, a média per capita dos gastos em cada área para os municípios que tinham dados disponibilizados no Finbra ${ }^{7}$ e, como outputs, o IDHM Longevidade e o IDHM Educação, é possível determinar os níveis de eficiência dos gastos em saúde e educação em relação aos seus resultados no IDHM. Após o cálculo inicial da eficiência dessas dimensôes, testa-se a presença de municípios outliers. ${ }^{8}$ Caso seja observada alguma DMU nessa condição, ela será removida da análise, devendo-se recalcular a eficiência sem a sua presença.

Para sinalizar a eficiência da renda utiliza-se o Índice de Gini já que, de certo modo, ele próprio é uma medida de eficiência (ao informar quão desigual é a distribuição de renda de um município, ou seja, quão ineficiente é a alocação da renda entre seus habitantes). Dado que o Gini é um índice em que valores menores indicam melhor distribuição de renda, utiliza-se (1 - Gini) como indicador da eficiência da distribuição, padronizando-se a análise, na qual valores maiores significam melhor eficiência.

$\mathrm{Na}$ posse dos três indicadores individuais de eficiência para cada dimensão de análise, é possível calcular a eficiência média dos municípios, que compreende a segunda etapa da heurística e que revela a dimensão adicional que diferencia o IDHM do IDHME. Mensura-se, assim, a média geométrica das três eficiências, já que ela faz com que uma baixa eficiência em quaisquer das dimensóes se reflita mais diretamente no índice, além de não permitir substitutibilidade perfeita entre os componentes, como ocorre na média simples.

Obtido o índice de eficiência média, este será utilizado em uma nova média geométrica, desta vez em conjunto com os demais componentes desagregados do IDHM. Esta última etapa abarca o cálculo do IDHME propriamente dito.?

6. Reconhece-se as limitações impostas pela restrição dos gastos apenas àqueles realizados pelas prefeituras, justamente porque 0 resultado final em cada área depende da interação entre todos os gastos públicos (aqui ainda inclusas as transferências estaduais e federais diretamente para os municípios ou os recursos destinados por essas esferas a setores específicos), bem como os dispêndios privados.

7. O Finbra compreende o relatório das informações sobre receitas e despesas dos municípios brasileiros, disponibilizado através da Secretaria do Tesouro Nacional (STN). A partir dele, para a presente análise, dos 5.565 municípios utilizados no Atlas de Desenvolvimento Humano no Brasil de 2010, 190 foram excluídos por falta de estatísticas orçamentárias nos anos analisados.

8. Dada a alta sensibilidade do DEA à presença de outliers e erros de amostra, é de grande importância a utilização de métodos para sua detecção. No presente artigo, utiliza-se um procedimento denominado jackstrap. Mais explicações encontram-se no apêndice $A$.

9. No que concerne às faixas de desenvolvimento, o IDHME será classificado conforme a categorização do IDHM. Neste sentido, existem cinco faixas: i) muito baixo, que engloba o intervalo entre 0 e 0,499; ii) baixo, entre 0,500 e 0,599; iii) médio, de 0,600 a 0,699; iv) alto, entre 0,700 e 0,799; e v) muito alto, para valores acima de 0,800. 
Deve-se destacar, entretanto, que a análise é realizada separadamente para estratos de municípios, classificados pela população a partir do método de clusterização $k$-means. ${ }^{10}$ Além das diferenças evidentes entre municípios maiores e menores (como acesso a recursos orçamentários e humanos, e a sua proporçáo per capita), a classificação advém do fato de que: i) os municípios podem se situar em fronteiras de eficiência diferentes, que não são diretamente comparáveis entre si ${ }^{11}$ e também de que: ii) não é conveniente que municípios muito diferentes entre si possam servir como benchmarks uns aos outros - por exemplo, afirmar que Belo Horizonte (com mais de 2 milhóes de habitantes) deveria se basear em Carmo da Cachoeira (com menos de 12 mil habitantes) para ser mais eficiente não parece ser factível.

\section{RESULTADOS E DISCUSSÃO}

\subsection{A eficiência dos municípios brasileiros}

A dimensão adicional que dará origem ao IDHME é inicialmente construída a partir do cálculo das eficiências individuais dos componentes do IDHM. Após a remoção dos outliers, detectados no cálculo da fronteira de eficiência dos gastos municipais com saúde e educação, as eficiências são recalculadas, verificando-se a possibilidade de os indicadores obtidos pertencerem a diferentes fronteiras de eficiência, que variam de acordo com o tamanho da unidade avaliada. Para tanto, os municípios foram divididos em três estratos, através da utilização da análise de clusters: i) estrato 1 , ou municípios pequenos, que compreende aqueles com até 23.425 habitantes; ii) estrato 2, ou municípios médios, que abrange aqueles que possuem entre 23.506 e 169.270 habitantes; e iii) estrato 3, ou municípios grandes, composto pelas unidades com mais de 170 mil habitantes. Desta forma, tais estratos são formados, respectivamente, por 4.029, 1.192 e 154 municípios.

Os resultados indicam que as observaçóes de tais grupos se situam em fronteiras diferentes, de modo que náo é possível fazer comparações adequadas utilizando uma única fronteira de eficiência para todos. Diante disso, são obtidas novas medidas de eficiência dos municípios para cada estrato separadamente. A tabela 1 traz as médias de eficiências da educação e da saúde, do indicador de Gini e da eficiência média para cada categoria, revelando que, de modo geral, os esforços orçamentários não estão significando resultados plenos nas áreas a que são destinados. Embora não seja possível comparar diretamente as eficiências entre os estratos, porque cada unidade avaliada tem o seu indicador de eficiência dependente da configuração do grupo a que pertence e das melhores práticas observadas no mesmo (o que é distinto para cada classe), é factível afirmar que, entre saúde e educação, o segundo item revela

10. Para mais detalhes, ver Johnson e Wichern (2007) e 0 apêndice A.

11. Para verificar essa possibilidade, aplica-se 0 teste $U$ de Mann-Whitney. Mais detalhes no apêndice $A$. 
médias superiores e, em relação ao tamanho das unidades analisadas, os grandes municípios parecem estar em situação melhor em relação aos seus benchmarks.

TABELA 1

Médias de eficiência segundo estratos

\begin{tabular}{ccccc}
\hline & Média de eficiência da educação & Média de eficiência da saúde & Média de (1-Gini) & Média de eficiência média $^{{ }^{1}}$ \\
\hline \multirow{2}{*}{ Estrato 1 } & 0,4327 & 0,4381 & 0,5140 & 0,4511 \\
& $(0,1402)$ & $(0,1442)$ & $(0,0666)$ & $(0,0882)$ \\
Estrato 2 & 0,5189 & 0,5489 & 0,4856 & 0,5058 \\
& $(0,1666)$ & $(0,1680)$ & $(0,0590)$ & $(0,0928)$ \\
Estrato 3 & 0,6776 & 0,5204 & 0,4786 & 0,5320 \\
& $(0,1922)$ & $(0,2029)$ & $(0,0567)$ & $(0,1002)$ \\
\hline
\end{tabular}

Fonte: Resultados da pesquisa.

Nota: ${ }^{1}$ A eficiência média é definida como a média geométrica entre a eficiência da saúde, da educação e (1-Gini).

Obs.: Desvio-padrão entre parênteses.

No primeiro estrato, sete municípios foram 100\% eficientes nos gastos com educação - Bastos, Herculândia, Macaubal, Monçôes e Piquete, localizados no estado de São Paulo; e Senhora dos Remédios e Dionísio, em Minas Gerais; outros quatro municípios o foram nos gastos com saúde - Campestre (MG), Cariré (CE), Rio Pomba (MG) e Rodeio (SC). No segundo estrato, seis cidades obtiveram eficiência máxima na educação - Fernandópolis (SP), Guararapes (SP), Joaçaba (SC), Passos (MG), São Cristóvão (SE) e São José de Ribamar (MA); enquanto na saúde foram sete - Bagé (RS), Jaú (SP), Leopoldina (MG), Sabará (MG), Santana do Paraíso (MG), Santo Antônio do Tauá (PA) e São Paulo de Olivença (AM). Por fim, no terceiro estrato, cinco municípios atingiram eficiência de $100 \%$ nos gastos educacionais - Niterói (RJ), Franca (SP), Aracaju (SE), Campina Grande (PB) e Feira de Santana (BA); ao passo que três o fizeram nos gastos com saúde Itaquaquecetuba (SP), Rio Grande (RS) e Uberlândia (MG). Quanto aos outliers, observaram-se 52 municípios nos gastos educacionais e outros 41 nos gastos com saúde. A tabela 2 apresenta a comparação das médias de gastos per capita e dos componentes de saúde e educação do IDHM para os municípios eficientes de cada estrato, outliers e da amostra geral.

TABELA 2

Médias de gastos per capita e dos componentes do IDHM

\begin{tabular}{lcccc}
\hline & Gastos com educação & IDHM Educação & Gastos com saúde & IDHM Saúde \\
\hline Eficientes do estrato 1 & 226,67 & 0,6871 & 156,01 & 0,8350 \\
Eficientes do estrato 2 & 234,50 & 0,7000 & 154,31 & 0,8357 \\
Eficientes do estrato 3 & 224,45 & 0,7000 & 204,35 & 0,8633 \\
Outliers & 299,39 & 0,7167 & 130,12 & 0,8436 \\
Geral & 406,10 & 0,5606 & 318,20 & 0,8028 \\
\hline
\end{tabular}

Fonte: Resultados da pesquisa. 
Como esperado, os municípios eficientes apresentam níveis de gastos consideravelmente menores do que a média total, bem como indicadores de desenvolvimento da educação e da saúde mais elevados. Já os outliers revelam desempenho superior aos municípios eficientes, principalmente no caso da saúde, em que seus níveis de gastos são menores que dos demais grupos. Justamente por apresentarem relaçóes muito diferenciadas de insumos e produtos é que tais municípios foram caracterizados como observaçóes discrepantes, que poderiam afetar em demasia o indicador de eficiência das demais observaçôes da amostra.

Em posse dos indicadores de eficiência de saúde e educação, e adicionando-se os dados referentes ao Índice de Gini, têm-se todos os elementos para o cálculo da eficiência média. No que se refere a este indicador, os municípios que revelaram maiores valores são apresentados na tabela 3, junto a seus respectivos IDHMs e rankings.

TABELA 3

Municípios com maior eficiência média

\begin{tabular}{llccc}
\hline Ranking eficiência média & \multicolumn{1}{c}{ Município } & Eficiência média & IDHM & Ranking IDHM' $^{1}$ \\
\hline 10 & Santa Bárbara do Oeste (SP) & 0,8333 & 0,78 & 960 \\
$2^{\circ}$ & São Cristóvão (SE) & 0,8068 & 0,66 & $2.730 \circ$ \\
$3^{0}$ & Rio Pomba (MG) & 0,7824 & 0,71 & $1.403^{\circ}$ \\
$4^{\circ}$ & São Miguel do Oeste (SC) & 0,7607 & 0,80 & 220 \\
50 & Sarandi (PR) & 0,7547 & 0,70 & $1.970 \circ$ \\
\hline
\end{tabular}

Fonte: Resultados da pesquisa.

Nota: ${ }^{1}$ Considerando os municípios da amostra final.

Os municípios com maior eficiência média apresentam níveis consideravelmente diferentes de desenvolvimento humano, enquadrando-se nas faixas de classificação do IDHM médio (São Cristóvão), IDHM alto (Santa Bárbara do Oeste, Rio Pomba e Sarandi) e IDHM muito alto (Sáo Miguel do Oeste). Isso fornece indícios de que a eficiência média está relacionada com outros indicadores, além daqueles incluídos na análise, que caracterizam a estrutura dos municípios, como pode ser o caso do mercado de trabalho, da distribuição dos habitantes, da localização e dos níveis educacionais.

\subsection{Fatores associados à eficiência média das municipalidades}

Diante da possibilidade da eficiência ser influenciada por diversos fatores socioeconômicos, realizaram-se regressôes tendo por finalidade correlacionar variáveis selecionadas com a eficiência média observada nas unidades avaliadas, modeladas 
a partir de uma regressão beta ${ }^{12}$ e uma regressão espacial. ${ }^{13}$ Os resultados são apresentados no apêndice $B$.

Ambos os modelos apontam em direçóes semelhantes, com diferenças residindo, na maior parte dos casos, apenas na dimensão dos parâmetros estimados. A exceção ocorre para o caso do IDHM, para o qual se observou mudança no sinal da correlação. Entre as variáveis selecionadas, o tamanho populacional é positivamente relacionado com a eficiência, de modo que municípios maiores tendem também a ser mais eficientes na gestão de seus recursos, evidenciando a existência de vantagens de escala para as atividades públicas nos municípios brasileiros. Esta relação positiva também é observada para o grau de urbanização, reforçando a ideia de ganhos de escala e de que a proximidade geográfica das pessoas permite um melhor aproveitamento da estrutura pública municipal.

No que concerne ao mercado de trabalho, duas são as constataçóes. Para a ocupação setorial, observa-se que uma maior proporção de trabalhadores (com 18 anos ou mais) nos setores de indústria e comércio está associada a níveis de eficiência média superiores, ao passo que o inverso ocorre para a proporção de trabalhadores no setor de serviços. Esta relação negativa também é observada, apesar de ir contra as expectativas iniciais, para o percentual de trabalhadores formais, com 18 anos ou mais. Neste caso, municípios onde o grau de formalização é maior apresentam, em média, menor eficiência.

Ressalta-se que, por se tratar de correlações parciais, tais resultados já estão controlados pelas demais covariadas do modelo. Para ilustrar isso, a tabela 4 traz informações sobre as médias dos empregos nos setores de serviços, indústria e comércio, bem como o grau médio de formalização, segundo os estratos. Essas informaçôes podem ser contrastadas com as respectivas eficiências médias apresentadas na tabela 1. Como é possível notar, municípios mais populosos também tendem a apresentar maior proporção de empregos nos três setores. Entretanto, a associação positiva com a eficiência só permanece para dois destes, indústria e comércio. Para os serviços, setor significativamente mais presente em municípios maiores, a associação com a eficiência obtida pelo modelo de regressão foi negativa, evidenciando que isso ocorre a despeito dos ganhos de escala populacional. Da mesma forma, o grau de formalização, que em média é mais elevado nos municípios de maior porte, apresentou, não obstante, associação negativa com a eficiência.

12. A regressão beta é indicada para casos em que a variável dependente assume valores entre 0 e 1. Para detalhes sobre o método, ver Ferrari e Cribari-Neto (2004).

13. A regressão espacial foi realizada após se constatar que a variável dependente apresenta dependência espacial (com / de Moran de 0,1135). A matriz de contiguidade espacial utilizada valeu-se da convenção binária da rainha de primeira ordem. Para detalhes sobre o método, ver Anselin (1988). 
TABELA 4

Empregos setoriais e grau de formalização, segundo os estratos (2010) (Em \%)

\begin{tabular}{lcccc}
\hline & $\begin{array}{c}\text { Participação média } \\
\text { na indústria }\end{array}$ & $\begin{array}{c}\text { Participação média } \\
\text { no comércio }\end{array}$ & $\begin{array}{c}\text { Participação média } \\
\text { nos serviços }\end{array}$ & Grau de formalização médio \\
\hline Estrato 1 & 9,10 & 9,32 & 30,84 & 41,65 \\
Estrato 2 & 11,51 & 14,09 & 36,17 & 48,10 \\
Estrato 3 & 13,31 & 17,40 & 47,51 & 66,50 \\
\hline
\end{tabular}

Fonte: Resultados da pesquisa, com dados obtidos de PNUD (2013).

No caso das ocupações setoriais, uma possível explicação para os resultados encontrados diz respeito à associação dos setores com a distribuição de rendimentos. Nesse sentido, os serviços tendem a apresentar uma grande amplitude, o que implica maiores indicadores de desigualdade no segmento. ${ }^{14} \mathrm{Tal}$ diferença pode gerar um impacto negativo na distribuição da renda municipal à medida que sua proporção na ocupação seja mais elevada em relação a setores com rendimentos relativamente mais homogêneos - como o comércio e a indústria.

No que concerne ao grau de formalização, há a possibilidade de que trabalhadores formais tenham maior tendência a procurar serviços da área da saúde, uma vez que seu posto de trabalho tende a ser mais protegido contra absenteísmos oriundos de questóes relacionadas à saúde pessoal e familiar. No caso dos informais, duas situaçóes distintas podem ocorrer, a depender do nível de rendimentos: i) informais de alta renda, como médicos e advogados que trabalham por conta própria, podem ter maior propensão a utilizar o sistema privado de saúde; e ii) informais de menor renda podem ser desencorajados a procurar serviços de saúde, públicos ou privados, pelo possível impacto de sua ausência sobre seus rendimentos e seu vínculo empregatício, comportamento muito associado à precariedade de sua ocupação.

A eficiência média está negativamente associada a três indicadores sociodemográficos: a incidência de gravidez na adolescência (percentual de mulheres entre 10 e 17 que tiveram filhos), a razão de dependência (percentual de indivíduos em idade não ativa em relação aos indivíduos em idade ativa) e, no modelo espacial, o percentual de alunos com atraso idade-série (dois ou mais anos de atraso, entre alunos de 6 a 17 anos no ensino básico). Todas elas implicam maiores encargos assistenciais para os municípios, seja através de demandas específicas decorrentes da precocidade gestacional e do envelhecimento populacional, especialmente na área de saúde, seja a partir de custos adicionais advindos de reprovaçóes ou início tardio na vida escolar. A gravidez na adolescência torna-se ainda mais problemática

14. Como verificado por Hoffmann e Ney (2004), em relação à indústria, e Silva e Oliveira (2015), em que os setores de serviços privados mercantis e serviços prestados às empresas apresentam índices de Gini entre os mais elevados, ficando atrás apenas da agricultura. 
porque, ao limitar as oportunidades das jovens mães, pode reforçar o ciclo intergeracional da pobreza, restringindo o acesso educacional (à mulher e aos filhos) e dificultando a inserçáo no mercado de trabalho, o que pode acentuar a incidência de pobreza e impactar na desigualdade de renda.

No que diz respeito à relação da eficiência média com o IDHM, os resultados diferiram entre os modelos. Enquanto no caso da regressão beta ambas apresentaram correlação negativa, isto é, municipalidades com menor IDH tendem a ser mais eficientes, no caso da regressão espacial a associação foi positiva, de modo que maiores indicadores de eficiência podem estar associados a cidades mais desenvolvidas. Diante desta discrepância, tomam-se os resultados do modelo espacial como sendo mais críveis, uma vez que levam em conta a estrutura de correlação espacial subjacente, fator que afeta as estimativas, impondo algumas ressalvas às conclusōes do modelo beta.

Ressalta-se, entretanto, que maior desenvolvimento náo necessariamente significa maior eficiência. Ao mesmo tempo que podem existir municipalidades relativamente desenvolvidas, mas onde a eficiência é baixa, também há a possibilidade de cidades pouco desenvolvidas conseguirem fazer uso eficiente dos recursos que têm à sua disposição - o que, contudo, não garante que elas venham a se desenvolver apenas em função disso. $\mathrm{O}$ uso eficiente dos recursos implica apenas que, em um dado momento, os resultados obtidos para aquele montante de insumos estão entre os melhores da amostra. Isso, contudo, não permite afirmar se tais resultados são satisfatórios do ponto de vista do desenvolvimento humano, tampouco ranquear o município entre os de maior IDHM do espaço amostral. Embora a eficiência possa ser entendida como condição necessária para alcançar níveis mais elevados de qualidade de vida para a população, ela certamente não é condição suficiente.

Convém notar ainda que o processo de dependência no espaço verificado é o de erro espacial. Em tal situaçáo, os termos de erro são espacialmente autocorrelacionados, o que ocorre devido a fatores exógenos como indutores da dependência. Em outras palavras, o contágio existente é aparente, e não real, já que não é produzido por um processo endógeno. Isso significa que a correlação espacial das eficiências médias tende a estar relacionada a fatores externos - como as trajetórias históricas de desenvolvimento econômico e territorial -, e não à transmissão de boas ou más práticas de gestão de recursos entre municípios vizinhos.

Em termos macrorregionais, nota-se uma predominância dos eficientes nas regiốes Sul e Sudeste. No Norte há apenas um município com eficiência média acima de 0,7 , e a maior parte da região $(73,8 \%)$ é composta por municípios com valor inferior à 0,5 para tal indicador. No Nordeste há três municípios com eficiência média acima de 0,7 , sendo que $73,7 \%$ apresentam valor abaixo de 0,5 . Na região Sul, quinze municípios possuem eficiência média acima de 0,7 , enquanto $56,4 \%$ deles tem tal valor abaixo de 0,5 . Para o Sudeste, tais grupos sáo compostos por 
27 e 992 (61,8\%) municípios, respectivamente; enquanto no Centro-Oeste assumem os valores de 2 e 331 (74,2\%) municípios. Tais informações são reforçadas pelos resultados do modelo de regressão beta, em que todas as regiôes apresentam eficiência média em geral mais elevada que a região de referência, o Nordeste, sendo que o Sul e o Sudeste são os casos onde a diferença assume maior magnitude. Ainda é possível notar, através do modelo, que municípios que pertencem às regiốes metropolitanas também tendem a apresentar maior eficiência média que suas contrapartes não metropolitanas.

\subsection{A distribuição espacial da eficiência}

Constatada a existência de dependência espacial, e visando ilustrar de maneira mais detalhada a distribuição dos indicadores de eficiência e do IDHME no território nacional, são apresentados a seguir mapas que apresentam diferentes visualizações destas variáveis, bem como de clusters locais. O mapa 1 evidencia, com maior nitidez, os resultados apresentados pelos modelos de regressão para as grandes regióes do país. Destaca-se, nesse caso, a maior concentração de municipalidades de eficiência elevada (acima de 0,7 ) no Sul e no Sudeste, ao passo que Nordeste e Norte tendem a ser dominados por municípios de pior desempenho nesse quesito (eficiência inferior a 0,6).

MAPA 1

Distribuição da eficiência média nos municípios brasileiros

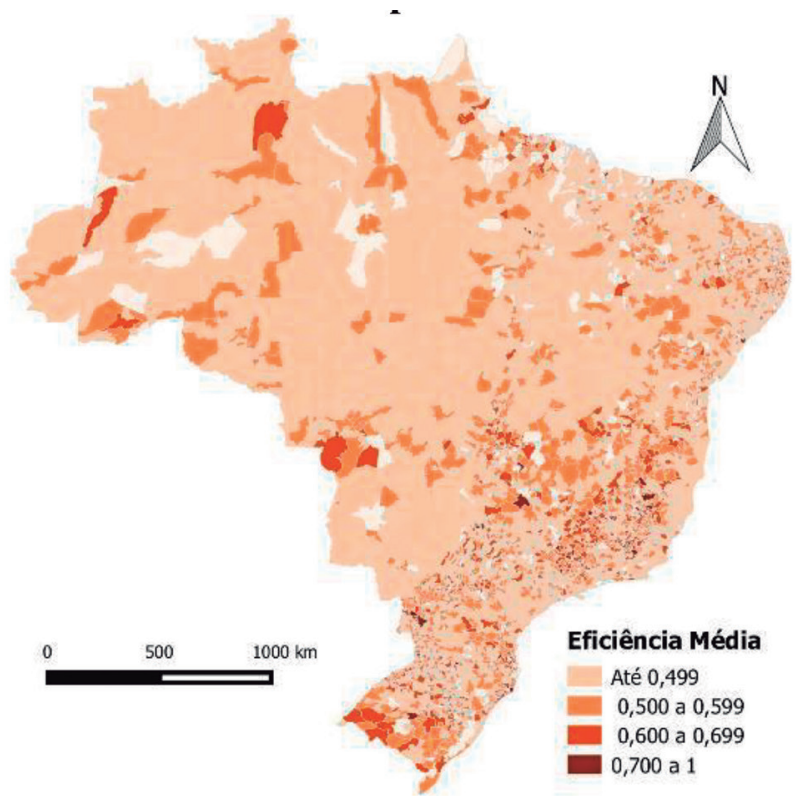

Elaboração dos autores.

Obs.: As áreas em branco referem-se aos municípios excluídos da análise por ausência de dados ou outliers. 
Através do cálculo da estatística $I$ de Moran Local é possível observar a presença de clusters de municípios com alta e baixa eficiência (mapa 2). Nota-se que há uma maior concentração dos clusters do tipo alto-alto (configurados por municípios com altos valores de eficiência média que são vizinhos de municípios na mesma situação) nas regiôes Sul e Sudeste, onde se observam as maiores manchas de contiguidade de tais agrupamentos; nas demais regióes observam-se casos mais esparsos. Os clusters baixo-baixo (compostos por municípios com baixos valores de eficiência média que são contíguos a outros em tal condição), por sua vez, apresentam distribuição menos concentradas entre as regióes. Contudo, cabe a ressalva de que o Norte possui maior proporção de tais clusters em relação às aglomerações alto-alto.

\section{MAPA 2}

\section{Clusters de eficiência média}

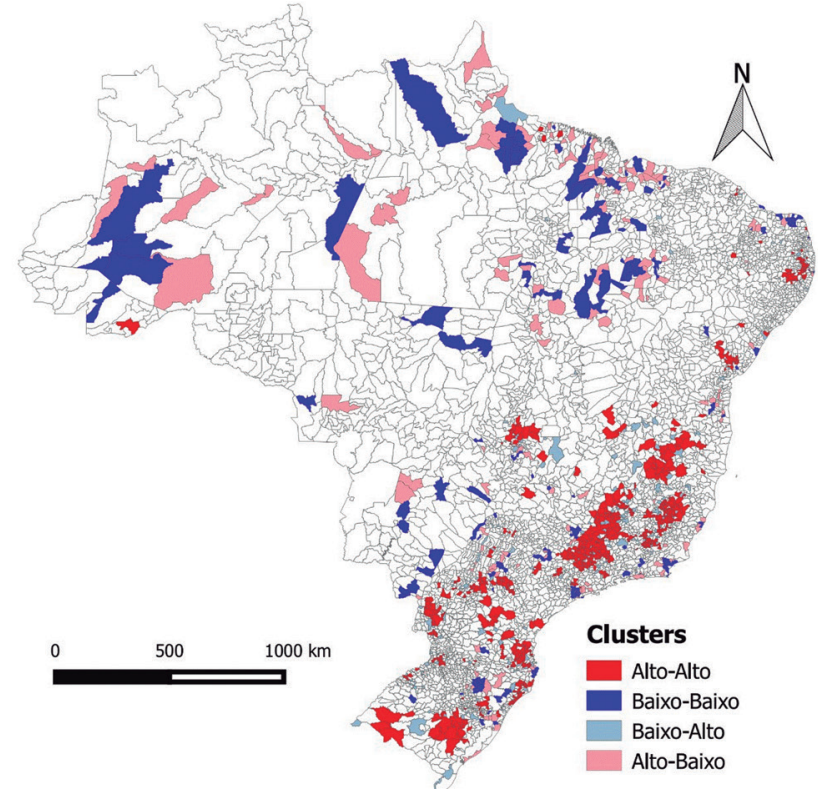

Elaboração dos autores.

A existência dos clusters alto-alto e baixo-baixo se traduz em correlação espacial positiva, quando uma municipalidade possui vizinhos cujo valor do indicador em questão é similar ao seu. Por sua vez, os clusters alto-baixo e baixo-alto implicam uma correlação negativa no espaço: no primeiro caso, unidades com elevado valor para o indicador estão contíguas a municípios onde este é baixo; no segundo, municipalidades com baixa eficiência são circundadas por vizinhos de 
desempenho elevado nessa dimensão. Como se nota no mapa 2, esses casos são menos frequentes, o que também se depreende do valor positivo calculado para o $I$ de Moran $(0,1135)$.

\subsection{0 Índice de Desenvolvimento Humano Municipal Eficiente}

A última etapa metodológica consiste na incorporação da eficiência média ao cálculo do IDHM, transformando-o, assim, em um índice com quatro componentes: IDHM Educação, IDHM Saúde, IDHM Renda e eficiência média. Tal inserção promoveu uma alteraçấo substancial nos valores finais do índice, como é apresentado na tabela 5, em que é comparado o novo indicador (IDHME) com o original (IDHM). Além disso, dada a necessidade de uma nova compatibilizaçáo para manter apenas os municípios com todas as observaçóes em cada indicador (isto é, aqueles que não foram excluídos como outliers da saúde, nem da educação), a amostra final foi reduzida a 5.286 municípios.

TABELA 5

Estatísticas do IDHME e do IDHM

\begin{tabular}{lll}
\hline & IDHME & IDHM \\
\hline Média & 0,6018 & 0,6599 \\
Desvio-padrão & 0,0604 & 0,0704 \\
Máximo & 0,7953 & 0,8370 \\
Mínimo & 0,4023 & 0,4180 \\
\hline
\end{tabular}

Fonte: Resultados da pesquisa.

As estatísticas dos índices revelam que o IDHME reduziu os valores do IDHM, tanto em termos de média e desvio-padrão, quanto de extremos. Tal resultado se deve ao fato de que a média do quarto elemento incorporado ao índicea eficiência média - é, em termos médios, menor do que os valores dos demais componentes, ocasionando, portanto, uma redução da heterogeneidade do índice original. De fato, apenas 113 municípios conseguiram obter um valor de IDHME superior ao de seu IDHM, indicando que, nestes casos, os esforços orçamentários podem estar promovendo melhorias na qualidade de vida de sua populaçáo que não são observadas pelas medidas do IDHM. A tabela 6 apresenta os municípios com maior IDHME, seus valores de IDHM e os respectivos rankings neste último. 
TABELA 6

Municípios com maior IDHME

\begin{tabular}{|c|c|c|c|c|}
\hline Ranking IDHME & Município & IDHME & IDHM & Ranking IDHM' \\
\hline 10 & Joaçaba (SC) & 0,7953 & 0,83 & $2^{\circ}$ \\
\hline $2^{\circ}$ & Santa Bárbara do Oeste (SP) & 0,7938 & 0,78 & $96^{\circ}$ \\
\hline 3은 & São Miguel do Oeste (SC) & 0,7908 & 0,80 & $22^{\circ}$ \\
\hline $4^{\circ}$ & Fernandópolis (SP) & 0,7825 & 0,80 & $31^{\circ}$ \\
\hline 5o & Brusque (SC) & 0,7824 & 0,80 & $370^{\circ}$ \\
\hline 60 & Americana (SP) & 0,7803 & 0,81 & 80 \\
\hline 7o & Uberlândia (MG) & 0,7748 & 0,79 & $51^{\circ}$ \\
\hline $8^{\circ}$ & Santa Maria (RS) & 0,7730 & 0,78 & $82^{\circ}$ \\
\hline 9o & Botucatu (SP) & 0,7706 & 0,80 & $23^{\circ}$ \\
\hline 100 & Cascavel (PR) & 0,7630 & 0,78 & $89 \circ$ \\
\hline
\end{tabular}

Fonte: Resultados da pesquisa.

Nota: ${ }^{1}$ Considerando os elementos da amostra.

Entre os dez municípios com melhor IDHME, nota-se que todos pertencem às regiôes Sudeste ou Sul, com predominância de São Paulo e Santa Catarina, e que já figuravam entre os cem melhores no ranking do IDHM para a amostra. Entretanto, alguns merecem destaque especial por terem conseguido galgar um número considerável de posiçóes, como é o caso de Santa Bárbara do Oeste (SP), que saiu do $96^{\circ}$ lugar no IDHM para o $2^{\circ}$ no IDHME, e também Santa Maria (RS) e Cascavel (PR), que subiram, respectivamente, do $82^{\circ}$ e $89^{\circ}$ lugares no IDHM para a $8^{\circ}$ e 10 - posiçóes no IDHME.

A distribuição geográfica do IDHME é apresentada no mapa $3 .{ }^{15}$ Reiterando graficamente o que já foi expresso por números, as regióes Sul e Sudeste possuem os maiores níveis de IDHME, tanto em termos médios quanto em distribuição dos municípios em cada faixa, de modo que quase dois terços das unidades municipais dessas regióes se situam em um nível de desenvolvimento médio. Os estados do Paraná, do Espírito Santo e de São Paulo não apresentaram nenhum município com IDHME muito baixo, e Santa Catarina é o estado com maior IDHME médio do país $(0,6578)$.

15. Como nenhum município apresentou IDHME acima de 0,8 , considerou-se valores acima de 0,7 como faixa de desenvolvimento superior. 
MAPA 3

A distribuição do IDHME nos municípios brasileiros

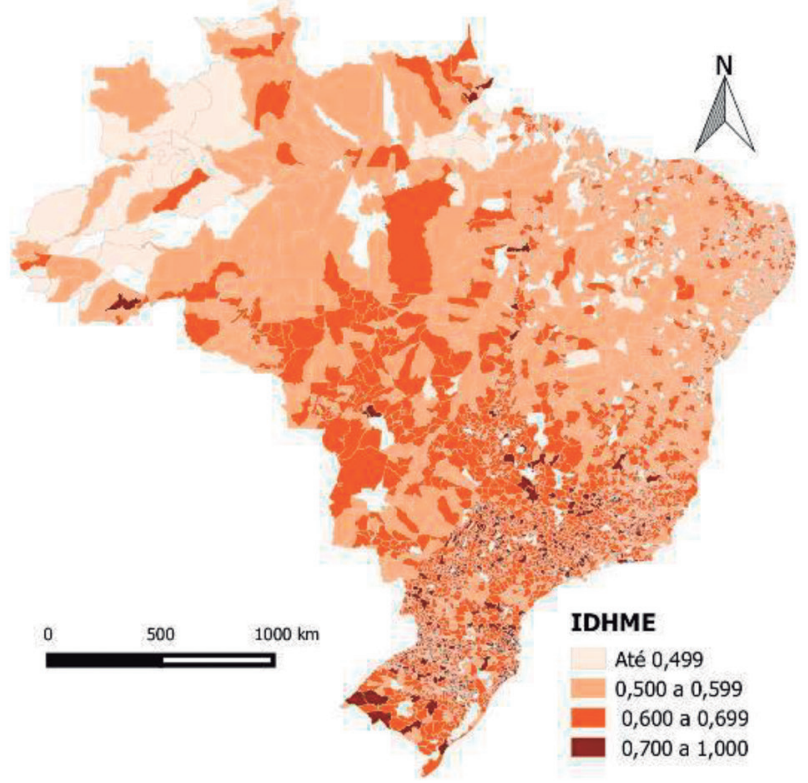

Elaboração dos autores.

Obs.: As áreas em branco referem-se aos municípios excluídos da análise por ausência de dados ou outliers.

As regióes em maior desvantagem em termos do IDHME são Nordeste e Norte, onde a maioria das cidades apresenta baixo valor para o índice. Nelas também se concentram municípios com IDHME muito baixo, localizados nos estados do Amazonas, do Acre e do Pará, em regióes basicamente de fronteira, nos quais, além de já apresentarem IDHM muito baixo, a eficiência média agrava tal situação. Em contrapartida, ainda na região Norte, os estados de Rondônia e do Amapá não apresentam nenhum município na faixa mais inferior do IDHME, bem como os estados nordestinos do Ceará e de Pernambuco. Contudo, todas as Unidades Federativas (UFs) dessas duas regiōes se encontram abaixo do IDHME médio para o Brasil $(0,6018)$. A região Centro-Oeste, por sua vez, situa-se em um meio termo entre as regióes anteriores, apresentando proporção de municípios com nível de desenvolvimento médio semelhante ao das regióes Sul e Sudeste, mas com menores incidências de níveis altos de desenvolvimento.

Em termos médios, essas informaçôes estão sintetizadas na tabela 7, que apresenta, além dos IDHMEs das regióes do Brasil, os valores associados aos estratos considerados na análise. Os municípios pequenos, que compreendem o estrato 1 , são os que possuem menores níveis de IDHME, sendo que mais da metade de tal grupo apresenta nível de desenvolvimento baixo, e praticamente todo o restante se situa na faixa do IDHME médio. Pelo fato do estrato 1 compreender $75 \%$ dos 
municípios analisados, tais indicadores tornam-se agravantes, demandando um olhar específico para tais municipalidades, levando em consideração suas peculiaridades e seus elementos comuns, com vistas a desenhar políticas de gestão de recursos mais adequadas a cada contexto. Por sua vez, o estrato 3, que abrange as grandes cidades, é o que apresenta melhores resultados, com mais de um terço dos municípios em níveis altos de desenvolvimento, e a maior parte dos demais em nível médio.

\section{TABELA 7}

Média e distribuição percentual dos níveis do IDHME segundo estratos e regiões

\begin{tabular}{lccccc}
\hline & $\begin{array}{c}\text { Média } \\
\text { IDHME }\end{array}$ & IDHME alto (\%) & IDHME Médio (\%) & IDHME baixo (\%) & $\begin{array}{c}\text { IDHME muito } \\
\text { baixo (\%) }\end{array}$ \\
\hline Estrato 1 & 0,5929 & 2,71 & 41,18 & 52,83 & 3,29 \\
Estrato 2 & 0,6238 & 15,26 & 45,95 & 36,70 & 2,09 \\
Estrato 3 & 0,6875 & 37,70 & 58,20 & 4,10 & 0,00 \\
Norte & 0,5634 & 1,22 & 21,27 & 67,97 & 9,54 \\
Nordeste & 0,5542 & 0,12 & 10,39 & 82,93 & 6,57 \\
Sul & 0,6428 & 13,70 & 65,83 & 20,29 & 0,17 \\
Sudeste & 0,6289 & 9,67 & 60,45 & 29,69 & 0,19 \\
Centro-Oeste & 0,6122 & 2,24 & 58,97 & 38,34 & 0,45 \\
\hline
\end{tabular}

Fonte: Resultados da pesquisa.

Como existem muitos municípios de pequena área territorial, sobretudo em regióes interioranas do Nordeste, Sul e Sudeste, aos quais contrastam municípios de grande área que ocorrem principalmente no Norte e no Centro-Oeste, a visualização da distribuição espacial dos atributos é parcialmente prejudicada. Assim, apresentaçóes alternativas aos mapas 1 e 3 podem ser observadas nos mapas 4 e 5 , nos quais o tamanho dos municípios é distorcido em função de seus valores de eficiência média e IDHME, respectivamente, de modo que os municípios com maiores valores de tais atributos tenham sua área aumentada, ao passo que o inverso ocorre com os menores valores. ${ }^{16} \mathrm{Tal}$ opçáo permite contornar o efeito do tamanho geográfico original das unidades, dando ênfase gráfica aos atributos dos municípios. Como consequência, tem-se um considerável ganho de tamanho para os municípios do Sudeste e do Sul em ambos os casos, enquanto os municípios do Norte e do Centro-Oeste são drasticamente reduzidos. Essas mudanças reforçam a constatação de que os maiores níveis de eficiência média e do IDHME apresentam um caráter de relativa concentração naquelas regiōes, ao passo que nestas, conjuntamente com o Nordeste, tais atributos tendem a ser menores.

16. A realização de tal distorção é feita através do software ScapeToad, que implementa o método proposto por Gastner e Newman (2004). 
MAPA 4

Distribuição da eficiência média com distorção do tamanho dos municípios

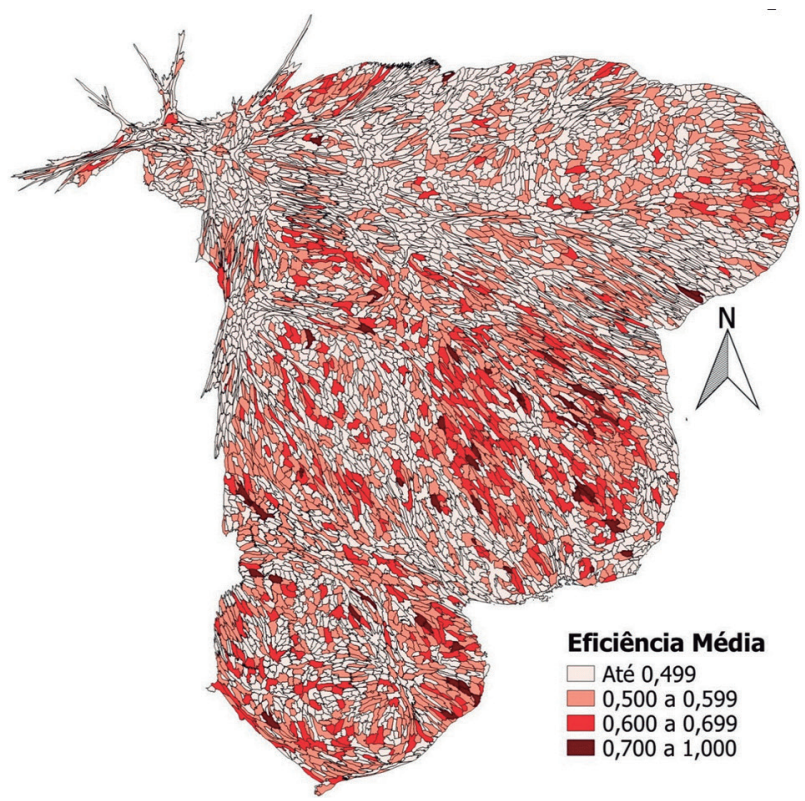

Elaboração dos autores.

MAPA 5

Distribuição do IDHME com distorção do tamanho dos municípios

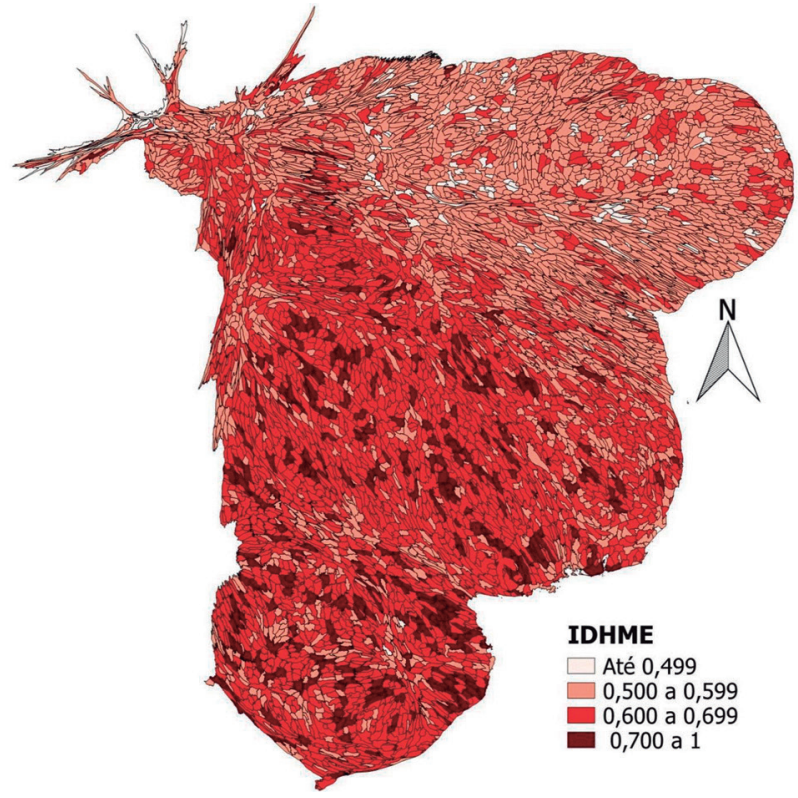


Em uma análise dos estados brasileiros através da média ponderada ${ }^{17}$ pela população dos IDHMEs dos municípios de cada UF (que muito se aproxima do IDH dos estados) observa-se que somente Santa Catarina apresenta um valor considerado alto para o IDHME. Em contrapartida, os estados nordestinos do Maranhão, de Alagoas, da Bahia e do Piauí, bem como o Pará, na regiáo Norte, possuem índices considerados baixos para o IDHME. Nessa análise, o Brasil tem um índice ponderado de 0,6513 , valor superado somente por Amapá na região Norte, por nenhum estado da região Nordeste, por Goiás, na região Centro-Oeste, por todos os estados da região Sul e pela maioria da região Sudeste, à exceção do Espírito Santo.

\section{CONSIDERAÇÕES FINAIS}

A utilização eficiente dos recursos públicos é condição necessária (embora não suficiente) para a consecução de melhores resultados no desenvolvimento municipal. Maior eficiência implica menor desperdício, o que, por sua vez, permite que cada unidade de insumo monetário não perdida por tal motivo possa ser melhor aplicada nas funções de responsabilidade do município. Uma vez que o fornecimento público dos serviços de saúde e educação, bem como políticas de distribuição de renda, permeiam o contexto socioeconômico nacional, o processo de desenvolvimento está intimamente associado ao desempenho da esfera estatal. Portanto, prover tal esfera com indicadores não somente do estágio de desenvolvimento humano dos municípios, mas também da competência destes em alocar os recursos públicos, torna-se essencial para balizar a tomada de decisóes que visem elevar o bem-estar da coletividade.

Nesse sentido, o índice proposto no presente artigo buscou integrar a dimensão da eficiência ao IDHM, fornecendo tanto uma medida da eficiência geral das municipalidades brasileiras na provisão dos serviços de saúde e educação, como promovendo um ajuste no indicador tradicional. O IDHME daí derivado, ao ser contrastado com o valor original do IDHM, pode fornecer aos gestores e munícipes uma medida de quanto se pode estar ganhando ou perdendo, em termos de valoraçáo dos níveis de desenvolvimento, em decorrência de como os recursos públicos são alocados. Além disso, as medidas desagregadas para a saúde e a educação também possibilitam identificar com maior precisão a fonte de eventuais ineficiências.

De modo geral, observa-se que a eficiência tem um caráter geográfico que se assemelha ao do desenvolvimento humano, de forma que municípios e regióes com maior IDHM tendem a apresentar melhor desempenho na alocação de recursos, como ilustra bem o fato de que os municípios do Sul e do Sudeste predominam

17. Em que $I D H M_{i}$ e $P$ op $i$ são, respectivamente, o IDHM e a população do município $i$ e $N$ é o número de municípios de cada estado. 
em tal aspecto. Embora os resultados dos modelos econométricos se apresentem discrepantes nesse sentido, aqui se tomam as estimativas do modelo espacial como mais consistentes, por levarem em conta a estrutura de correlaçóes entre municípios que apresentam alguma vizinhança. Seguindo tal especificação, constata-se que níveis mais elevados de desenvolvimento humano se associam com maiores índices de eficiência. Sinaliza-se, ainda, a possibilidade de que a relação desenvolvimento-eficiência funcione em sentido duplo, em um processo de feedbacks que criam um círculo virtuoso: maior eficiência alocativa da esfera pública permite obter melhores níveis de desenvolvimento humano, e estes, por sua vez, podem incrementar a capacidade de otimizar a aplicaçáo dos recursos.

Entre os elos que oportunizam que tal círculo virtuoso se complete, a infraestrutura e a solidez institucional são imprescindíveis. Uma corrente é tão forte quanto seu elo mais fraco. Fortalecer os aparatos institucionais da democracia transparência, vigor da lei, accountability, participação cívica, garantias das liberdades civis e econômicas -, bem como criar uma rede de infraestruturas que viabilizem tais aparatos e que insiram os municípios em um contexto de maior conectividade com seus vizinhos, com a nação e com o mundo, são vitais para que maiores eficiências possam ser alcançadas e para que o desenvolvimento humano possa florescer.

\section{REFERÊNCIAS}

ANSELIN, L. Spatial econometrics: methods and models. Dordrecht: Kluwer Academic Publishers, 1988.

CASTRO, C. E. T. Avaliaçáo da eficiência gerencial de empresas de água e esgotos brasileiros por meio da envoltória de dados (DEA). Dissertação (Mestrado) - Pontifícia Universidade Católica, Rio de Janeiro, 2003.

CHARNES, A.; COOPER, W. W.; RHODES, E. L. Measuring the efficiency of decision making units. European Journal of Operational Research, v. 2, n. 6, p. 429-444, 1978.

DALBERTO, C. R. et al. P. Índice de Desenvolvimento Humano Eficiente: uma mensuração alternativa do bem-estar das naçóes. Pesquisa e Planejamento Econômico, v. 45, n. 2, p. 337-363, 2015.

FAÇANHA, L. O.; MARINHO, A. Instituiçóes de ensino superior governamentais e particulares: avaliação comparativa de eficiência. Rio de Janeiro: Ipea, 2001. (Texto para Discussão, n. 813).

FERRARI, S. L. P.; CRIBARI-NETO, F. Beta regression for modelling rates and proportions. Journal of Applied Statistics, v. 31, n. 7, p. 799-815, 2004. 
GASTNER, M. T.; NEWMAN, M. E. J. Diffusion-based method for producing density equalizing maps. Proceedings of the National Academy of Sciences of the United States of America, v. 101, n. 20, p. 7499-7504, 2004.

GONDIM, S. S. Análise da eficiência técnica das redes hospitalares públicas estadual e municipal em Fortaleza. Dissertação (Mestrado) - Universidade Federal do Ceará, Fortaleza, 2008.

HICKS, N.; STREETEN, P. Indicators of development: the search for a basic needs yardstick. World Development, v. 7, n. 6, p. 567-580, 1979.

HOFFMANN, R.; NEY, M. G. Desigualdade, escolaridade e rendimentos na agricultura, indústria e serviços, de 1992 a 2002. Economia e Sociedade, v. 13, n. 2, p. 51-79, 2004.

JOHNSON, R. A.; WICHERN, D. W. Applied Multivariate Statistical Analysis. 6. ed. Upper Saddle River: Prentice Hall, 2007.

LINS, M. E. et al. O uso da análise envoltória de dados (DEA) para avaliação de hospitais universitários brasileiros. Ciência e Saúde Coletiva, v. 12, n. 4, p. 985-998, 2007.

MARINHO, A. Avaliação da eficiência técnica nos serviços de saúde dos municípios do estado do Rio de Janeiro. Rio de Janeiro: Ipea, 2001 (Texto para Discussão, n. 842).

MEZA, L. A. Data envelopment analysis (DEA) na determinaçáo da eficiência dos programas de pós-graduação do Coppe/UFRJ. Dissertação (Mestrado) Universidade Federal do Rio de Janeiro, Rio de Janeiro, 1998.

PNUD - PROGRAMA DAS NAÇÓES UNIDAS PARA O DESENVOLVIMENTO. Atlas do Desenvolvimento Humano no Brasil. 2013. Disponível em: <www.atlasbrasil.org.br>. Acesso em: 9 jan. 2016.

STN - SECRETARIA DO TESOURO NACIONAL. Finbra - Finanças do Brasil. Disponível em: <https://siconfi.tesouro.gov.br/siconfi>. Acesso em: 20 jan. 2015.

SILVA, I. C.; OLIVEIRA, M. A. S. Estrutura produtiva e distribuição de renda no Brasil: uma abordagem insumo-produto. Revista Pesquisa \& Debate, v. 26, n. 2, p. 169-189, 2015.

SILVA, M. M.; FERNANDES, E. Um estudo da eficiência dos programas de pós-graduação em engenharia no Brasil. Revista Rede Avaliaçáo Instituiçáo da Educaçáo Superior, v. 6, n. 3, p. 53-66, 2001.

TORRES, H. G.; FERREIRA, M. P.; DINI, N. P. Indicadores sociais: por que construir novos indicadores como o IPRS. Sáo Paulo Perspectiva, v. 17, n. 3/4, p. 80-90, 2003. 
YAMADA, J. N. Economias de escala e eficiência de gastos na saúde: novas evidências. Dissertação (Mestrado) - Fundação Getulio Vargas (FGV), São Paulo, 2011.

\section{BIBLIOGRAFIA COMPLEMENTAR}

BANKER, R. D.; CHARNES, A.; COOPER, W. W. Some models for estimating technical and scale inefficiencies in data envelopment analysis. Management Science, v. 30, n. 9, p. 1078-1092, 1984.

BANKER, R. D.; ZHENG, Z. E.; NATARAJAN, R. DEA-based hypothesis tests for comparing two groups of decision making units. European Journal of Operation Research, v. 206, n. 1, p. 231-238, 2010.

SOUSA, M. C. S.; STOSIC, B. D. Jackstrapping DEA Scores for Robust Efficiency Measurement. Brasília: UnB, 2003. (Texto para Discussão, n. 291).

. Technical efficiency of the Brazilian municipalities: correcting nonparametric frontier measurements for outliers. Journal of Productivity Analysis, v. 24, n. 2, p. $157-181,2005$. 


\section{APÊNDICE A}

\section{INFORMAÇÕES ADICIONAIS DAS TÉCNICAS EMPREGADAS NO TRABALHO}

\section{ANÁLISE ENVOLTÓRIA DE DADOS}

A análise envoltória de dados (DEA) tem por mérito analisar a eficiência relativa de unidades produtoras que, na literatura relacionada com modelos DEA, são tratadas por unidades tomadoras de decisão (do inglês, decision making unit-DMU). Por unidade produtora entende-se qualquer sistema produtivo que transforme insumos em produtos, podendo ser firmas, setores da economia, regiôes ou gestores públicos municipais, como é o caso deste artigo.

Para estimar e analisar a eficiência relativa das DMUs, o DEA utiliza a definição segundo a qual nenhum produto pode ter sua produção aumentada sem que sejam aumentados os seus insumos ou, de forma alternativa, quando nenhum insumo pode ser diminuído sem ter que diminuir a produção de algum produto (ótimo de Pareto). Charnes, Cooper e Rhodes (1978) dão início a esta abordagem considerando que existem $k$ insumos e $m$ produtos para cada $n$ DMUs. A partir disso, são construídas duas matrizes: a matriz $X$ de insumos $(k \times n)$ e a matriz $Y$ de produtos $(m \times n)$, representando os dados de todas as $n$ DMUs. Na matriz $X$, cada linha revela um insumo e cada coluna representa uma DMU, enquanto na matriz $Y$, cada linha faz referência a um produto e cada coluna, uma DMU. Para ambas, é necessário que os coeficientes sejam não negativos e que cada linha e cada coluna contenham, pelo menos, um coeficiente positivo. Assim, para a $i$-ésima DMU, são representados os vetores $x_{i}$ e $y_{i}$ para insumos e produtos, respectivamente, de modo que, para cada DMU, pode ser possível obter uma medida de eficiência, que é a razão entre todos os produtos e todos os insumos. Tem-se:

$$
\text { Eficiência da DMUi }=\frac{u^{\prime} y_{i}}{v^{\prime} x_{i}}=\frac{u_{1} y_{1 i}+u_{2} y_{2 i}+\ldots+u_{m} y_{m i}}{v_{1} x_{1 i}+v_{2} x_{2 i}+\ldots+v_{k} x_{k i}}
$$

em que: $u$ é um vetor $(m \times 1)$ de pesos nos produtos e $v$ é um vetor $(k \times 1)$ de pesos nos insumos.

O pressuposto utilizado pelo método é o de que a medida de eficiência requer um conjunto comum de pesos que será aplicado em todas as DMUs, o que dificilmente é conseguido em virtude das diferentes formas pelas quais estas unidades estabelecem os valores para insumos e produtos. O DEA com orientação a insumos e pressuposição de retornos constantes à escala, procura minimizar o uso proporcional das quantidades de insumos, mantendo fixos os níveis de produção. 
O modelo para o cálculo da eficiência de uma DMU, proposto por Charnes, Cooper e Rhodes (1978), pode ser representado da seguinte forma:

$\operatorname{MIN}_{\theta, \lambda} \theta$,

sujeito a:

$$
\begin{aligned}
& -y_{i}+Y \lambda \geq 0, \\
& \theta x_{i}-Y \lambda \geq 0, \\
& \lambda \geq 0,
\end{aligned}
$$

em que: $\theta$ representa a eficiência da $i$-ésima DMU, de modo que, quando igual a 1 , a DMU será eficiente. $O$ parâmetro $\lambda$ corresponde a um vetor coluna formado por valores que identificam a soluçáo ótima. Para uma DMU ineficiente, os valores de $\lambda$ serão os pesos utilizados na combinação linear de outras DMUs eficientes, que influenciam a projeção da DMU ineficiente sobre a fronteira calculada. Isto significa que, para uma unidade ineficiente, existe pelo menos uma unidade eficiente, cujos pesos calculados fornecerão a DMU virtual da unidade ineficiente mediante combinação linear. Em outras palavras, o problema de programação linear apresentado na equação (2) é resolvido $n$ vezes, uma vez para cada DMU e, como resultado, apresenta os valores de $\theta$ e $\lambda$. Caso a DMU seja ineficiente, os valores de $\lambda$ fornecem os "pares" daquela unidade, ou seja, as DMUs eficientes que serviram de referência (benchmark) para a DMU ineficiente.

A hipótese de retornos constantes à escala é bastante apropriada quando todas as DMUs estão operando em escala ótima. O modelo de retornos variáveis (BCC) foi proposto por Banker, Charnes e Cooper (1984), como um desdobramento daquele com retornos constantes (CCR), consistindo em adicionar uma restrição de convexidade do tipo $N_{1}^{\prime} \lambda=1$, em que $N_{1}$ é um vetor $(n \times 1)$ de algarismos unitários. Sendo uma nova metodologia de fronteira de eficiência que admite retornos variáveis de escala, substitui o axioma da proporcionalidade entre inputs e outputs pela máxima da convexidade, permitindo que DMUs que operam com baixos valores de inputs tenham retornos crescentes de escala e as que operam com altos valores tenham retornos decrescentes de escala.

\section{TESTES NÃO PARAMÉTRICOS DE FRONTEIRAS DE EFICIÊNCIA E A DETECÇÃO DE OUTLIERS}

Antes de executar os modelos para o cálculo das medidas de eficiência, é preciso verificar se os municípios, com níveis populacionais diferentes, fazem parte de uma mesma fronteira de eficiência ou se cada nível populacional gera sua própria fronteira. Para verificar se há diferenças entre as fronteiras de eficiência dos municípios quando separados pela populaçáo, procede-se com o teste não paramétrico $U$ de Mann-Whitney. O teste avalia se, entre dois grupos de variáveis aleatórias, uma 
delas é estocasticamente maior que outra, sendo assim aplicado para verificar se duas amostras independentes pertencem ou não a uma mesma população (Banker, Zheng e Natarajan, 2010).

A clusterização, por sua vez, consiste em um método de estatística multivariada, cujo objetivo é agrupar observaçóes de uma amostra de acordo com critérios de semelhança entre elas. $\mathrm{O}$ método $k$-means consiste em um algoritmo que permite classificar as observaçóes em $k$ grupos (clusters), atribuindo cada uma ao grupo com o centroide (média) mais próximo, utilizando como métrica a distância euclidiana (Johnson e Wichern, 2007).

Gerados os grupos de análise e dada a sensibilidade do DEA à amostra utilizada, é necessário proceder com o teste de detecção de outliers. Para isso, faz-se uso da metodologia desenvolvida por Sousa e Stosic (2003; 2005), que combina dois métodos de reamostragem e é denominada de jackstrap. Nela, tenta-se mensurar a influência individual de cada DMU, de tal modo a identificar as observaçóes que influenciam sobremaneira a fronteira de eficiência. ${ }^{18}$

\section{REFERÊNCIAS}

BANKER, R. D.; CHARNES, A.; COOPER, W. W. Some models for estimating technical and scale inefficiencies in data envelopment analysis. Management Science, v. 30, n. 9, p. 1078-1092, 1984.

BANKER, R. D.; ZHENG, Z. E.; NATARAJAN, R. DEA-based hypothesis tests for comparing two groups of decision making units. European Journal of Operation Research, v. 206, n. 1, p. 231-238, 2010.

CHARNES, A.; COOPER, W. W.; RHODES, E. L. Measuring the efficiency of decision making units. European Journal of Operational Research, v. 2, n. 6, p. 429-444, 1978.

DALBERTO, C. R. et al. P. Índice de Desenvolvimento Humano Eficiente: uma mensuração alternativa do bem-estar das naçóes. Pesquisa e Planejamento Econômico, v. 45, n. 2, p. 337-363, 2015.

JOHNSON, R. A.; WICHERN, D. W. Applied Multivariate Statistical Analysis. 6. ed. Upper Saddle River: Prentice Hall, 2007. 
SOUSA, M. C. S.; STOSIC, B. D. Jackstrapping DEA Scores for Robust Efficiency Measurement. Brasília: UnB, 2003. (Texto para Discussão, n. 291). . Technical efficiency of the Brazilian municipalities: correcting nonparametric frontier measurements for outliers. Journal of Productivity Analysis, v. 24, n. 2, p. 157-181, 2005. 
APÊNDICE B

\section{TESTES E MODELOS DE REGRESSÃO}

TABELA B. 1

Testes de multiplicador de Lagrange para escolha do modelo espacial

\begin{tabular}{lc}
\hline Teste & Estatística $^{2}$ \\
\hline ML (lag) & $301,9757^{* * *}$ \\
ML-robusto (lag) & $50,7917^{* * *}$ \\
ML (erro) & $1365,7955^{* *}$ \\
ML-robusto (erro) & $1114,6116^{* * *}$ \\
\hline
\end{tabular}

Fonte: Resultados da pesquisa.

Nota: ${ }^{1}$ Tanto o teste robusto de lag quanto o de erro foram significativos, mas a estatística foi consideravelmente mais elevada para este último. Além disso, tal fato pode afetar também o resultado dos demais testes, de modo que considerou-se mais parcimonioso adotar uma modelagem apenas para o erro espacial.

Obs.: ${ }^{* * *}$ significativo a $1 \%$.

TABELA B.2

Resultados dos modelos de regressão

\begin{tabular}{|c|c|c|}
\hline Variável & Regressão Beta² & Regressão espacial² \\
\hline População total (In) & $\begin{array}{r}0,1500 \\
(0,0060)^{* \star *}\end{array}$ & $\begin{array}{r}0,0450 \\
(0,0016)^{* * *}\end{array}$ \\
\hline IDHM & $\begin{array}{r}-2,1450 \\
(0,1831)^{* * *}\end{array}$ & $\begin{array}{r}0,1060 \\
(0,0204)^{* * *}\end{array}$ \\
\hline Grau de formalização & $\begin{array}{r}-0,0047 \\
(0,0005)^{* * *}\end{array}$ & $\begin{array}{r}-0,0007 \\
(0,0001)^{* * *}\end{array}$ \\
\hline Ocupação na indústria & $\begin{array}{r}0,0056 \\
(0,0007)^{* * *}\end{array}$ & $\begin{array}{r}0,0012 \\
(0,0002)^{* * *}\end{array}$ \\
\hline Ocupação no comércio & $\begin{array}{r}0,0192 \\
(0,0018)^{* * *}\end{array}$ & $\begin{array}{r}0,0034 \\
(0,0004)^{* * *}\end{array}$ \\
\hline Ocupação nos serviços & $\begin{array}{r}-0,0077 \\
(0,0008)^{\star \star \star}\end{array}$ & $\begin{array}{r}-0,0024 \\
(0,0002)^{* * *}\end{array}$ \\
\hline Gravidez na adolescência & $\begin{array}{r}-0,0170 \\
(0,0024)^{* * *}\end{array}$ & $\begin{array}{r}-0,0022 \\
(0,0005)^{* * *}\end{array}$ \\
\hline Razão de dependência & $\begin{array}{r}-0,0079 \\
(0,0009)^{* * *}\end{array}$ & $\begin{array}{r}0,0002 \\
(0,0002)\end{array}$ \\
\hline Atraso escolar & $\begin{array}{r}-0,0049 \\
(0,0008)\end{array}$ & $\begin{array}{c}-0,0002 \\
(0,0002)\end{array}$ \\
\hline Grau de urbanização (\%) & $\begin{array}{r}0,3103 \\
(0,0343)^{* * *}\end{array}$ & $\begin{array}{r}0,0431 \\
(0,0083)^{* * *}\end{array}$ \\
\hline Norte & $\begin{array}{r}0,1074 \\
(0,0176)^{\star * *}\end{array}$ & - \\
\hline Sudeste & $\begin{array}{r}0,1829 \\
(0,0161)^{* * *}\end{array}$ & - \\
\hline
\end{tabular}




\begin{tabular}{lcc} 
(Continuação) & & \\
\hline Variável & Regressão Beta ${ }^{2}$ & Regressão espacial $^{2}$ \\
\hline Sul & 0,2873 & - \\
\hline Centro-Oeste & $(0,0189)^{* * *}$ & - \\
\hline Região metropolitana & 0,0944 & \\
\hline Constante & $(0,0194)^{* *}$ & - \\
\hline Lambda ${ }^{* *}$ & 0,0375 & 0,0076 \\
& $(0,0170)^{* *}$ & $(0,0020)^{* * *}$ \\
\hline
\end{tabular}

Fonte: Resultados da pesquisa, com dados obtidos de PNUD (2013).

Notas: ${ }^{1} 0$ parâmetro lambda indica a intensidade e a significância do termo de erro espacial.

2 Erros-padrão robustos entre parênteses.

Obs.: ${ }^{* \star *}$ significativo a $1 \% ;{ }^{* *}$ significativo a $5 \%$; e ${ }^{*}$ significativo a $10 \%$.

\section{REFERÊNCIA}

PNUD - PROGRAMA DAS NAÇÓES UNIDAS PARA O DESENVOLVIMENTO. Atlas do Desenvolvimento Humano no Brasil. 2013 Disponível em: <www.atlasbrasil.org.br/2013/>. Acesso em: 9 jan. 2016.

Data da submissão: 6/5/2017

Primeira decisão editorial em: 3/1/2019

Última versão recebida em: 23/2/2019

Aprovação final em: 11/3/2019 
